\title{
Effectiveness of art therapy on level of stress and anxiety among paediatric oncology patients
}

\author{
Priti Pramod Patil ${ }^{1}$, *Rajashri Karale ${ }^{1}$, Vaishali R Mohite ${ }^{1}$, Prakash Naregal ${ }^{1}$
}

Sri Lanka Journal of Child Health, 2021; 50(3): 459-464

\begin{abstract}
Background: Children hospitalized for a long duration due to cancer often feel isolated and this results in increased levels of stress and anxiety. Hospitalization causes fear, apprehension and physical conditions like pain, which could be a stressor for children. Art therapy helps cope with stress and traumatic experiences.
\end{abstract}

Objectives: To assess the effectiveness of art therapy on the levels of stress and anxiety among paediatric oncology patients

Method: A total of 30 children were allocated equally into the experimental and control groups in this quantitative study. The experimental group was provided art therapy (drawing, painting and ceramic art) while the control group was provided routine therapy. Post assessment levels of stress and anxiety was done using structured questionnaires of perceived stress scale and the Hamilton anxiety rating scale. Data was analysed using paired and unpaired t-test, Wilcoxon sign rank test and Chisquare test. $\mathrm{p}<0.05$ was taken as significant.

Results: Effect of art therapy in the experimental group showed a significant difference in the mean stress and anxiety scores in post-test $(\mathrm{p}=0.00069$ and $\mathrm{p}=0.000642$ ) as compared to control. Comparison of anxiety scores with any type of cancer showed a significance of $p=0.010$ in experimental group in comparison to control at post-test.

Conclusions: Art therapy was an effective strategy in the reduction of stress and anxiety levels among children with cancer.

DOI: http://doi.org/10.4038/sljch.v50i3.9696

${ }^{1}$ Krishna Institute Nursing Sciences, Krishna Institutes of Medical Sciences, India

*Correspondence: kimssubmission1@gmail.com

iD https://orcid.org/0000-0002-4073-862X (Keceived on 01 August 2020: Accepted after revision on 22 September 2020)

The authors declare that there are no conflicts of interest

Personal funding was used for the project.

Open Access Article published under the Creative

Commons Attribution CC-BY (cc) (i) License
(Key words: Anxiety, art therapy, neoplasm)

\section{Introduction}

Around 300,000 children 0-19 years of age are diagnosed with cancer annually ${ }^{1}$. In India, cancer is the ninth common cause of deaths in 5-14 year old children $^{2}$. Over $80 \%$ paediatric cancer cases are cured in high-income countries, whereas only about $20 \%$ are cured in low to middle-income countries ${ }^{3,4}$. Children diagnosed with cancer may experience stress in various aspects like physical effects of therapy, academic, social and emotional consequences which influence mental health and quality of life $\mathrm{e}^{5-7}$. Anxiety in children might result in a limited vocabulary to express their thoughts and emotions $^{8}$. Children might experience persisting negative moods due to cancer-related fears, posttraumatic stress and depression ${ }^{9}$. In addition, anxiety and stress could lead to aggression in children. They also have higher levels of anger and are more impulsive compared to healthy children ${ }^{10}$. Art therapy has been considered as one of the effective tools in coping with stress and anxiety in recent years $^{11}$. It is the therapeutic use of art that helps cope with stress and traumatic experiences. Cognitive abilities can increase through creating and reflecting art on art products and processes ${ }^{12}$. There are very limited studies conducted to prove the effectiveness of art therapy in relation to stress and anxiety in children with cancer.

\section{Objectives}

To assess existing level of stress and anxiety in paediatric oncology patients, to assess effectiveness of art therapy and to compare the effectiveness of art therapy on levels of stress and anxiety in children of experimental versus control group.

\section{Method \\ Study design}

This quantitative study was carried out at various cancer treating hospitals in children aged 7-12 years, diagnosed with cancer from $3^{\text {rd }}$ October 2018 to $4^{\text {th }}$ November 2018. This study was designed on the basis of quasi-experimental pre-test post-test control group. Male and female children aged 7-12 years, hospitalized with the diagnosis of any type of cancer and children and parents who understood Marathi or Hindi were included. Children who were unconscious and those who were physically or mentally handicapped were excluded. 
A total of 30 children, with 15 children in each group (experimental and control) were included. Recruitment was by non-probability convenience sampling till the sample size was reached. Sample size was calculated based on effect size of stress which was 0.29 between the group and within the group with an error set at $5 \%$ and power of the study was $85 \%$ to obtain a total group size of 30 patients. Intervention in the form of art therapy by an expert in the field, which included drawing, painting, and ceramic art for a duration of 30 minutes/day for 5 successive days was provided to the children in the experimental group. Suggestions and practice were given to the kid by the expert. The control group received their routine care as per hospital policy. Pre- and post-assessment levels of stress and anxiety was done on the seventh day. Demographic data was collected with a standard proforma and anxiety was measured with the Hamilton scale and stress with the perceived stress scale. The standard of questionnaire tools were validated and the required modifications were done. Finalized tool included 10 items of demographic data, stress assessment scale and anxiety assessment tool.

Structured questionnaire for demographic data: A standard proforma included age of child, gender, religion, type of family, education of child, education of parent, occupation of parent, family income, duration of illness, treatment modalities and art selected by the subjects. The answers were obtained from the parents.

Perceived stress scale: standard questionnaire by Barbara White (2014), using a 4-point Likert scale to assess the level of stress among subjects in both groups, was used. Higher scores indicated higher stress perception. The stress levels were identified with the behavioural patterns of the children ${ }^{13}$.

Hamilton anxiety rating scale (HAM-A): standard questionnaire by Hamilton (1959) in a 5-point Likert scale to assess the levels of anxiety was used. Total score ranged from 0-56 and according to the range, anxiety levels were divided into mild $(<17)$, mild to moderate (18-24) and moderate to severe $(25-30)^{14}$.

Ethical issues: Ethical clearance was obtained from the Institutional Ethics Committee of Krishna Institutes of Medical Sciences, Deemed University, Karad, India (No. KIMSDU/IEC/04/2018). Written informed consent was taken from parents of children participating in the study.

\section{Statistical analysis}

Data were analysed using descriptive and inferential statistics. Demographic variables were analysed using paired t-test, unpaired t-test, Wilcoxon sign rank test and Chi-square test and was represented by frequency and percentage. Mean and standard deviation were used to analyse the level of stress and anxiety in pre-test and post-test. Paired t-test and unpaired t-test were used to analyse and interpret effectiveness of the art therapy on level of stress and anxiety among paediatric oncology patients. Unpaired t-test was used to find out the association of demographic data on stress and anxiety level.

\section{Results}

Among 30 children with cancer, 15 each were included in the experimental and control groups. Frequency distribution of basic demographic variables are presented in Table 1.

Table 1: Frequency distribution of basic demographic variables

\begin{tabular}{|c|c|c|c|}
\hline \multicolumn{2}{|c|}{ Demographic Variable } & \multirow{2}{*}{$\begin{array}{c}\begin{array}{c}\text { Experimental group } \\
(n=15)\end{array} \\
\text { Frequency }(\%)\end{array}$} & \multirow{2}{*}{$\begin{array}{c}\text { Control group } \\
(n=15)\end{array}$} \\
\hline Variable & Sub-Categories & & \\
\hline \multirow[t]{2}{*}{ Age } & 7 - 9 Years & $07(46.7)$ & $09(60.0)$ \\
\hline & $10-12$ Years & $08(53.3)$ & $06(40.0)$ \\
\hline \multirow[t]{2}{*}{ Gender } & Male & $09(60.0)$ & $11(73.3)$ \\
\hline & Female & $06(40.0)$ & $04(26.7)$ \\
\hline \multirow[t]{2}{*}{ Religion } & Hindu & $11(73.3)$ & $10(66.7)$ \\
\hline & Other & $04(26.7)$ & $05(33.3)$ \\
\hline \multirow[t]{2}{*}{ Type of family } & Nuclear & $08(53.3)$ & $07(46.7)$ \\
\hline & Other & $07(46.7)$ & $08(53.3)$ \\
\hline \multirow[t]{2}{*}{ Education of child } & $1 \mathrm{st}-4$ th & $10(66.7)$ & $12(80.0)$ \\
\hline & 5 th -7 th & $05(33.3)$ & $03(20.0)$ \\
\hline \multirow[t]{2}{*}{ Education of parent } & Primary to Middle school & $40(26.7)$ & $05(33.3)$ \\
\hline & Higher Secondary and more & $11(73.3)$ & $10(66.7)$ \\
\hline \multirow[t]{2}{*}{ Occupation of parent } & Own Job & $06(40.0)$ & $07(46.7)$ \\
\hline & Job Private or Govt. sector & $09(60.0)$ & $08(53.3)$ \\
\hline \multirow[t]{2}{*}{ Family income } & $<15,000$ & $06(40.0)$ & $05(33.3)$ \\
\hline & $\geq 15,000$ & $09(60.0)$ & $10(66.7)$ \\
\hline
\end{tabular}


Majority of subjects in both groups were in the 1012 year age group, $46.7 \%$ in the experimental group versus $60 \%$ in control group respectively. Most of the subjects in both groups were males $(60 \%$ vs $73.3 \%$ ). Majority had chemotherapy followed by radiotherapy or surgery and chemotherapy. With respect to the intervention of art, $40 \%$ in the experimental group expressed ceramic art as their favourite whilst in the control group, $40 \%$ expressed painting as the favourite art. Whereas $46.7 \%$ children had a duration of illness of 1-2 years in the experimental group, in the control group $46.7 \%$ of the children had a duration of illness $<1$ year.

Distribution of stress and anxiety levels on the basis of pre-test and post-test in experimental and control groups is presented in Table 2 .

Table 2: Frequency distribution of level of stress and anxiety according to pre-test and post-test among subjects in experimental and control groups

\begin{tabular}{|c|l|c|c|c|}
\hline \multirow{2}{*}{ Group } & \multicolumn{1}{|c|}{ Parameter } & Mild & Moderate & Severe \\
\hline \multirow{4}{*}{ Experimental } & \multicolumn{1}{|c|}{ Stress } & Frequency (\%) & Frequency (\%) & Frequency (\%) \\
\cline { 2 - 5 } & Pre-test & $09(60.0)$ & $03(20.0)$ & $03(20.0)$ \\
\cline { 2 - 5 } & Post-test & $10(66.7)$ & $05(33.3)$ & $0(0)$ \\
\hline \multirow{2}{*}{ Control } & Pre-test & $10(66.7)$ & $02(13.3)$ & $03(20.0)$ \\
\cline { 2 - 5 } & Post-test & $09(60.0)$ & $03(20.0)$ & $03(20.0)$ \\
\hline \multirow{2}{*}{ Group } & Anxiety & Frequency (\%) & Frequency (\%) & Frequency (\%) \\
\hline \multirow{2}{*}{ Control } & Pre-test & $03(20.0)$ & $08(53.3)$ & $04(26.7)$ \\
\cline { 2 - 5 } & Post-test & $10(66.7)$ & $05(33.3)$ & $0(0)$ \\
\cline { 2 - 5 } & Pre-test & $03(20.0)$ & $09(60.0)$ & $03(20.0)$ \\
\hline
\end{tabular}

With respect to the level of stress in the experimental group, none of the children experienced severe stress after art therapy, whereas in the control group $20 \%$ of children experienced severe stress. In terms of anxiety, none of the children showed any evidence of severe anxiety in the experimental group after art therapy, whereas, in the control group, after routine treatment, $26.7 \%$ of subjects experienced severe levels of stress which was slightly higher as compared to pre-test. Overall results demonstrated reduction of stress and anxiety in the experimental group as compared to the control group.

The effectiveness of art therapy on levels of stress and anxiety in the experimental group revealed a statistically significant difference in the mean stress scores $(p=0.000693)$ and anxiety scores $(p=0.000642)$ in post-test after art therapy for the experimental group. With regards to the control group, there was no statistically significant difference observed in pre and post-test (Table 3 ).

Table 3: Effectiveness of art therapy on levels of stress and anxiety among experimental and control groups

\begin{tabular}{|l|l|c|c|c|}
\hline \multicolumn{1}{|c|}{ Parameters } & \multicolumn{1}{|c|}{ Group } & Pre-test & Post-test & p-value \\
\hline \multirow{2}{*}{ Stress } & Experimental & $19 \pm 5.21$ & $15 \pm 4.15$ & $0.000693^{\mathrm{W}}$ \\
\cline { 2 - 5 } & Control & $18 \pm 6.21$ & $18 \pm 5.84$ & $0.4125^{\mathrm{t}}$ \\
\hline \multirow{2}{*}{ Anxiety } & Experimental & $22 \pm 4.47$ & $16 \pm 4.09$ & $0.000642^{\mathrm{W}}$ \\
\cline { 2 - 5 } & Control & $21 \pm 3.96$ & $21 \pm 3.91$ & $0.4922^{\mathrm{W}}$ \\
\hline
\end{tabular}

W: Wilcoxon signed rank test; $t$ : $t$-test

Comparison of anxiety scores among subjects with any type of cancer showed a statistically significant difference $(\mathrm{p}=0.010)$ in the mean of post-test anxiety score in the experimental group as compared to the control group. There was no statistically significant difference observed in mean stress score in the experimental and control groups (Table 4). 
Table 4: Comparison of pre-test and post-test stress and anxiety scores among subjects with any type of cancer between experimental and control group

\begin{tabular}{|l|c|c|c|}
\hline \multicolumn{1}{|c|}{ Parameters } & Experimental Group & Control Group & p-value \\
\hline Stress & $19 \pm 5.21$ & $18 \pm 6.21$ & $0.6145^{\mathrm{t}}$ \\
\hline Pre-test & $15 \pm 15.4$ & $18 \pm 5.84$ & $0.1445^{\mathrm{W}}$ \\
\hline Post-test & $22 \pm 4.47$ & $21 \pm 3.96$ & $0.6923^{\mathrm{W}}$ \\
\hline Anxiety & $16 \pm 4.09$ & $21 \pm 3.91$ & $0.01046^{\mathrm{W}}$ \\
\hline Pre-test & \multicolumn{3}{|l}{} \\
\hline Post-test &
\end{tabular}

$W$ : Wilcoxon signed rank test; $t$ : $t$-test

$*_{p}<0.05$ considered as statistically significant

\section{Discussion}

Stress and anxiety in children due to cancer affect the mental health and life quality of both children and family. The need for art therapy will terminate mental stress as art tends to have a calming effect. Communication through various forms of art has been demonstrated as an appropriate tool for children who experienced stress and anxiety during cancer treatment. Hence it was necessary to design an interventional programme related to the lack of comprehensive therapy and prevalence of mental disturbances in children with cancer. The Hamilton scale which is greatly used in adults, is equally effective in children ${ }^{15}$. In the current study, the majority were male in both groups (experimental $60 \%$ and control $73.3 \%$ ). These findings were similar to three other studies which also reported a majority of male children with childhood cancer ${ }^{15-17}$. The reporting of more males in our study could be due to various genetic associations with sex specificity ${ }^{18}$. In contrast, another study by Koolaee $\mathrm{AK}$, et $a l^{19}$ reported a majority of females $(53.3 \%)$ compared to males $(46.6 \%)$. With regards to the intensity of anxiety in the present study, $53.3 \%$ of subjects had moderate anxiety as compared to $60 \%$ in the control group. These results were in accordance with the study by Abdelaziz MT, et $a l^{20}$ which reported $62 \%$ of subjects with symptoms of anxiety. The study by Koolaee AK, et al ${ }^{19}$ also reported $60.9 \%$ of subjects with anxiety which was similar to the current study. In the current study, the result of higher levels of anxiety could be due to illness duration in children, fear or underlying pain.

The effectiveness of art therapy on mean levels of stress and anxiety scores post-test revealed a significant difference of $\mathrm{p}=0.000693$ and $\mathrm{p}=0.000642$ as compared to the control group which showed no statistically significant difference at posttest. Abdulah DM, et al ${ }^{21}$ reported effectiveness of art therapy based on painting and handcrafting on various dimensions of health-related quality of life. The results of their study reported fewer stressful feelings $(\mathrm{p}=0.004)$ and better overall health status $(\mathrm{p}<0.001)$ of life in children with cancer. Sao KP, et $a l^{16}$ conducted a study on the effectiveness of art therapy on levels of anxiety and showed significant decrease in anxiety levels at post-test in the experimental group with $\mathrm{p}<0.05$. Khadar $\mathrm{MG}$, et $a l^{22}$, in a study on art therapy based on painting reported reduction in symptoms of seasonal affective disorder in the experimental group as compared to control group, which produced a positive effect on reduction in anxiety levels among subjects suffering from cancer.

Comparison of post-test mean and SD anxiety scores of experimental group with control group in the present study showed a significant reduction in levels of anxiety $(p=0.010)$ which showed that art therapy significantly reduced anxiety levels. In support to the findings of the current study, a study by Dalei SR, et $a l^{23}$ showed similar findings with regards to anxiety levels among 60 preschool children in selected hospitals and reported a statistically significant difference of $p=0.025$ in the art therapy group at post-test compared to control group. However, the study showed more effectiveness of play therapy as compared to art therapy though no significant difference was observed.

There were no studies reported in contradiction to the findings of the present study with respect to the effectiveness of art therapy. Hence, this study could be considered a review for future studies in relation to the effectiveness of art therapy. However, there are a few limitations in this study. The results could be warily generalized due to limited sample size. There was a lack of involvement of patients with other chronic illness and psycho-physiological disorders to evaluate the stress and anxiety levels in children with comparison to the illness in the current study. Small sample size was a serious limitation in the current study which can be attributed to the hurdles like identification of children with chronic illness and obtaining consent from their parents. Further studies with large samples are warranted to evaluate the efficacy of art therapy in comparison to other therapies on stress and anxiety in childhood cancer. Studies on larger sample size in comparison with alternative therapies like music therapy, yoga and play therapy can be conducted in future to evaluate the efficacy of the interventions. Farreaching comparative studies on the effect of various other interventions with art therapy at different age 
groups is still needed in this domain to arrive at more conclusive outcomes.

\section{Conclusions}

Art therapy was an effective strategy in the reduction of stress and anxiety levels among children with cancer.

\section{References}

1. Steliarova-Foucher E, Colombet M, Ries $\mathrm{LAG}$, et al. International incidence of childhood cancer, 2001-10: a populationbased registry study. Lancet Oncology 2017; 18(6): 719-31.

https://doi.org/10.1016/S14702045(17)301 86-9

2. Summary-Report on Causes of Death: 2001-03 in India. Available from:

http://censusindia.gov.in/Vital_Statistics/S ummary_Report_Death_01_03.pdf. (Accessed May 1, 2020).

3. Gupta S, Howard SC, Hunger SP, Antillon FG, Metzger ML, Israels T, et al. Treating childhood cancer in low- and middleincome countries. In: Gelband $\mathrm{H}$, Jha $\mathrm{P}$, Sankaranarayanan $\mathrm{R}$, et al, editors. Cancer: Disease Control Priorities, Third Edition (Volume 3). Washington (DC): The International Bank for Reconstruction and Development / The World Bank; 2015 Nov 1. Chapter 7.

https://doi.org/10.1596/978-1-4648-0349-

9 ch7

PMCid: PMC4389499

4. Howard SC, Zaidi A, Cao X, Weil O, Bey $\mathrm{P}$, Patte $\mathrm{C}$, et al. The My Child Matters programme: effect of public-private partnerships on paediatric cancer care in low-income and middle-income countries. Lancet Oncology 2018; 19(5): 252-66. https://doi.org/10.1016/S14702045(18)301 23-2

5. Jones BL. The challenge of quality care for family caregivers in paediatric cancer care. Seminars in Oncology Nursing 2012; 28(4): 213-20.

https://doi.org/10.1016/j.soncn.2012.09.00 3

PMid: 23107178

6. Montgomery M, Huang S, Cox CL, Leisenring WM, Oeffinger $\mathrm{KC}$, Hudson MM, et al. Physical therapy and chiropractic use among childhood cancer survivors with chronic disease: impact on health-related quality of life. Journal of Cancer Survivorship 2011; 5(1): 73-81. https://doi.org/10.1007/s11764-010-01519

PMid: 20922492 PMCid: PMC3062253

7. Alderfer MA, Hodges JA. Supporting siblings of children with cancer: A need for family-school partnerships. School Mental Health 2010; 2(2): 72-81. https://doi.org/10.1007/s12310-010-90274

PMid: 20582154 PMCid: PMC2889700

8. Rollins JA. Tell me about it: Drawing as a communication tool for children with cancer. Journal of Pediatric Oncology Nursing 2005; 22(4): 203-21. https://doi.org/10.1177/104345420527710 3

PMid: 15994339

9. Yi JC, Syrjala KL. Anxiety and depression in cancer survivors. Medical Clinics of North America 2017; 101(6): 1099-13. https://doi.org/10.1016/j.mcna.2017.06.00 5

PMid: 28992857 PMCid: PMC5915316

10. Durualp E, Altay NA. Comparison of emotional indicators and depressive symptom levels of school-age children with and without cancer. Journal of Pediatric Oncology Nursing 2012; 29(4): 232-9.

https://doi.org/10.1177/104345421244661 6

PMid: 22797685

11. Hart J. Art therapy and cancer care. Alternative and Complementary Therapies 2010; 16(3): 140-4.

https://doi.org/10.1089/act.2010.16306

12. Akila A. Effectiveness of art therapy on stress among patients with cancer. Journal of Dental and Medical Sciences 2019; 18(7): 12-3.

13. White B. The perceived stress scale for children: A pilot study in a sample of 153 children. International Journal of Pediatrics and Child Health 2014; 2: 4552.

https://doi.org/10.12974/23118687.2014.0 2.02 .4

14. Hamilton M. The assessment of anxiety states by rating. British Journal of Medical Psychology 1959; 32: 50-5. 
https://doi.org/10.1111/j.20448341.1959.t b00467.x

15. Leichsenring, F. Cognitive-behavioral therapy and psychodynamic psychotherapy: Techniques, efficacy, and indications. American Journal of Psychotherapy 2006; 60(3): 233.

https://doi.org/10.1176/appi.psychotherap y.2006.60.3.233

PMid: 17066756

16. Sao KP, Maurya A. Effectiveness of art therapy on level of anxiety among hospitalized children. International Journal of Science and Research 2017; 6(8): 974-7.

17. Wallace J, Packman W, Huffman LC, Horn $\mathrm{B}$, Cowan $\mathrm{M}$, Amylon $\mathrm{MD}$, et al. Psychosocial changes associated with participation in art therapy interventions for siblings of paediatric hematopoietic stem cell transplant patients. Journal of the American Art Therapy Association 2014; 31(1): 4-11. https://doi.org/10.1080/07421656.2014.87 3685

18. Dorak MT, Karpuzoglu E. Gender differences in cancer susceptibility: an inadequately addressed issue. Frontiers in Genetics 2012; 3: 268.

19. Koolaee AK, Vazifehdar R, Bahari F, Akbari ME. Impact of painting therapy on aggression and anxiety of children with https://doi.org/10.3389/fgene.2012.00268 PMid: 23226157 PMCid: PMC3508426 cancer. Caspian Journal of Pediatrics 2016; 2(2): 135-41.

20. Abdelaziz MT, Mona M. The relationship between PTSD, anxiety and depression in Palestinian children with cancer and mental health of mothers. Journal of Psychology and Brain Studies 2017; 1(2): 9

21. Abdulah DM, Abdulla BMO. Effectiveness of group art therapy on quality of life in paediatric patients with cancer: A randomized controlled trial. Complementary Therapies in Medicine 2018; 41: 180-5.

https://doi.org/10.1016/j.ctim.2018.09.020 PMid: 30477836

22. Khadar MG, Babapour J, Sabourimoghaddam $\mathrm{H}$. The effect of art therapy based on painting therapy in reducing symptoms of separation anxiety disorder (SAD) in elementary school boys. Procedia - Social and Behavioral Sciences 2013; 84: 1697-703. https://doi.org/10.1016/j.sbspro.2013.07.0 16

23. Dalei SR, Nayak GR. Compare the effect of art therapy and play therapy in reducing anxiety among hospitalized preschool children in selected hospitals. Journal of Biomedical Science 2019; 6(3): 5. https://doi.org/10.3126/jbs.v6i3.26823 